\title{
Seletividade de agrotóxicos utilizados em pessegueiro sobre ovos e pupas do predador Chrysoperla externa
}

\author{
Selectivity of pesticides used in peach orchards on eggs and pupae of the predator Chrysoperla \\ externa
}

\author{
Rodolfo Vargas Castilhos ${ }^{\mathrm{I}^{*}}$ Anderson Dionei Grützmacher ${ }^{\mathrm{I}}$ Paulo Ricardo Baier Siqueira ${ }^{\mathrm{I}}$ \\ Ítalo Lucas de Moraes ${ }^{\mathrm{I}}$ Cleiton Jair Gauer ${ }^{\mathrm{I}}$
}

\section{RESUMO}

Objetivou-se com este trabalho avaliar a seletividade de dezenove agrotóxicos utilizados na cultura do pessegueiro sobre ovos e pupas do predador Chrysoperla externa em condições laboratoriais (temperatura $25 \pm 1^{\circ} \mathrm{C}$, umidade relativa $70 \pm 10 \%$ e fotofase 14 horas). Os agrotóxicos foram pulverizados diretamente sobre ovos e pupas por meio de uma torre de Potter, utilizando a máxima dosagem recomendada para a cultura do pessegueiro. Foi avaliada a viabilidade de ovos e pupas, além da fecundidade e fertilidade de adultos emergidos de pupas tratadas. Os agrotóxicos foram classificados para ovos em função da redução na eclosão e, para pupas, em função do efeito total, conforme a escala de toxicidade proposta pela IOBC. A maioria dos agrotóxicos avaliados ( 8 inseticidas, 8 fungicidas e 2 herbicidas) se mostrou inócua (classe 1) a ovos e pupas, com redução na eclosão de larvas e efeito total em pupas inferiores a 30\%. A exceção se deu para o inseticida óleo mineral, que reduziu a eclosão de larvas em $69,55 \%$ quando pulverizado em ovos e proporcionou efeito total em pupas de $36,22 \%$, sendo classificado como levemente nocivo (classe 2) a ovos e pupas de C. externa.

Palavras-chave: controle biológico, controle químico, inimigo natural, manejo integrado de pragas, Prunus persica.

\section{ABSTRACT}

This research aimed to evaluate the effect of nineteen pesticides used in peach orchards on eggs and pupae of the predator Chrysoperla externa in bioassays carried under laboratory conditions (temperature of $25 \pm 1^{\circ} \mathrm{C}$, relative humidity $70 \pm 10 \%$ and 14 hours photophase). The pesticides were directly sprayed on eggs and pupae trough a Potter tower using the maximum recommended dosage for peach orchards. It was evaluated eggs and pupae viability, in addition to fecundity and fertility of adults emerged from treated pupae. The pesticides were classified to eggs according to reduction in eggs hatch, and to pupae according to the total effect into IOBC toxicity categories. Most of pesticides evaluated ( 8 insecticides, 8 fungicides and 2 herbicides) were harmless (category 1) to eggs and pupae, with a reduction in eggs hatch and total effect to pupae lower than 30\%, except for the insecticide mineral oil, which reduced eggs hatch in $69.55 \%$ and caused a total effect of $36.22 \%$ in pupae, being therefore classified as slightly harmful (category 2) to eggs and pupae of C. externa.

Key words: biological control, chemical control, natural enemy, integrated pest management, Prunus persica.

\section{INTRODUÇÃO}

O controle químico na cultura do pessegueiro é prática constantemente utilizada para manutenção da sanidade dos pomares. Insetos fitófagos como as moscas-das-frutas Anastrepha fraterculus (Wiedemann) e Ceratitis capitata (Wiedemann) (Diptera: Tephritidae), a mariposa-oriental Grapholita molesta (Busck) (Lepidoptera: Tortricidae), pulgões, ácaros, cochonilhas, e o gorgulho Sitophilus zeamais (Motschulsky) (Coleoptera: Curculionidae) são exemplos de artrópodes-praga comuns à cultura do pessegueiro, e são frequentemente controlados com inseticidas de amplo espectro de ação, como organofosforados e piretroides (SALLES, 1998; NÖRNBERG et al., 2013). Aliado a isso, muitas regiões produtoras de pêssego, principalmente no Sul do Brasil, possuem alta precipitação pluviométrica, alta umidade relativa do ar e ventos fortes durante a primavera e verão, o que favorece a ocorrência e disseminação de doenças, obrigando o persicultor a intensificar o uso de fungicidas (FACHINELLO et al., 2003).

IDepartamento de Fitossanidade, Universidade Federal de Pelotas (UFPel), CP 354, 96010-900, Pelotas, RS, Brasil. E-mail: rvcastilhos@ hotmail.com. *Autor para correspondência. 
O uso constante de agrotóxicos em pomares de pessegueiro pode afetar negativamente organismos não-alvo, como os inimigos naturais, que auxiliam na manutenção das populações de pragas a níveis aceitáveis. Em programas de Manejo Integrado de Pragas (MIP), é importante que seja priorizado o uso de agrotóxicos que sejam seletivos ou causem o menor impacto possível aos inimigos naturais, pois, assim, a atividade exercida por estes insetos benéficos será preservada e eles irão auxiliar, juntamente com o controle químico, na regulação das populações de insetos-praga.

Dentre os inimigos naturais que podem estar presentes em pomares de pessegueiro, destacase o crisopídeo Chrysoperla externa (Hagen) (Neuroptera: Chrysopidae), importante predador de pragas da cultura como pulgões, ácaros e cochonilhas, além de ovos e pequenas lagartas (FREITAS, 2002; SCHUBER et al., 2008). Segundo ATANASSOV et al. (2003), os crisopídeos estão entre os predadores mais abundantes em pomares de pessegueiro, e estes podem exercer predação sobre 15 a $30 \%$ dos ovos de G. molesta presentes em pomares.

Levando-se em conta a importância de $\boldsymbol{C}$. externa como agente de controle biológico, estudos de seletividade de agrotóxicos sobre as diferentes fases de desenvolvimento deste predador devem ser realizados para auxiliar no MIP em pessegueiro. Os estágios de ovo e pupa, por serem imóveis e se localizarem muitas vezes em locais desprotegidos, perto dos focos de infestação da praga, são expostos a pulverizações diretas de agrotóxicos nos pomares (SOARES et al., 2002). Dessa forma, a seletividade fisiológica de agrotóxicos sobre ovos e pupas se faz importante, pois qualquer impacto drástico em um destes estágios pode inibir o ciclo de desenvolvimento e impedir o estabelecimento de uma população de $\boldsymbol{C}$. externa em um agroecossistema. Sendo assim, este trabalho teve como objetivo avaliar a seletividade de agrotóxicos utilizados em pomares de pessegueiro sobre ovos e pupas do predador $C$. externa.

\section{MATERIAL E MÉTODOS}

Os bioensaios foram conduzidos através de uma adaptação de metodologia, proposta por MEDINA et al. (2003). Os ovos e pupas de C. externa utilizados nos bioensaios foram oriundos de uma criação massal mantida em laboratório (temperatura $25 \pm 1^{\circ} \mathrm{C}$, umidade relativa $70 \pm 10 \%$ e fotofase 14 horas), conforme metodologia proposta por CARVALHO \& SOUZA (2000). Para alimentação da fase larval, foram oferecidos ovos de Anagasta kuehniella (Zeller) (Lepidoptera: Pyralidae), enquanto que, para os adultos, foi oferecida uma dieta artificial descrita por VOGT et al. (2000).

Ovos e pupas com aproximadamente 24 horas de idade foram diretamente pulverizadas com 19 agrotóxicos (9 inseticidas, 8 fungicidas e 2 herbicidas) utilizados no pessegueiro, utilizandose a máxima dosagem recomendada para a cultura (AGROFIT, 2010). Os agrotóxicos, ingrediente ativo - produto comercial (máxima dosagem da formulação comercial registrada para a cultura em g ou mL $100 \mathrm{~L}^{-1}$ ou $\mathrm{L} \mathrm{ha}^{-1}$ / concentração do ingrediente ativo na calda, em \%) avaliados foram: os inseticidas abamectina - Vertimec 18 EC (80 / 0,001), chlorantraniliprole Altacor (14 / 0,005), deltametrina - Decis 25 EC (40 / 0,001), fentiona - Lebaycid 500 (100/ 0,050), fosmete - Imidam 500 WP (200 / 0,100), lufenurom - Match EC (100 / 0,005), malationa - Malathion 1000 EC (200 / 0,200), novalurom - Rimon 100 EC (40 / 0,004) e óleo mineral - Assist (2000 / 1,512); os fungicidas azoxystrobina - Amistar 500 WG (20 / 0,010), captana - Orthocide 500 (240 / 0,120), ciproconazol Alto 100 (20 / 0,002), dodina - Dodex 450 SC (175 / 0,080), enxofre - Kumulus DF (600 / 0,480), folpete - Folpan Agricur 500 WP (250 / 0,125), mancozebe Manzate 800 (200 / 0,160) e tebuconazole - Folicur 200 EC $(100 / 0,020)$ e os herbicidas dicloreto de paraquate - Gramoxone (3 / 0,300) e glifosato Roundup $(6 / 1,080)$. Na testemunha, ovos e pupas foram tratados via pulverização de água destilada. A pulverização se deu através de uma torre de Potter, previamente calibrada para realizar um depósito de calda de $2 \pm 0,2 \mathrm{mg} \mathrm{cm}^{-2}$.

No bioensaio com ovos, foram utilizadas quatro repetições com 24 ovos cada, em um total de 96 ovos por tratamento, enquanto que, para pupas, foram utilizadas quatro repetições com seis pupas cada, totalizando 24 pupas por tratamento. Após a pulverização e secagem da calda, ovos e pupas tratados foram individualizados e acondicionados em uma câmara climática tipo BOD, ajustada para as mesmas condições nas quais os insetos foram criados. Passados aproximadamente cinco dias, a viabilidade de ovos foi avaliada e, consequentemente, a redução na eclosão de larvas (R.E.L.), proporcionada por cada agrotóxico, foi calculada. Para pupas, após aproximadamente uma semana, determinou-se a viabilidade e a redução na emergência de adultos (R.E.A.) causada pelos agrotóxicos. Os adultos emergidos de pupas tratadas foram avaliados para verificação de possíveis efeitos subletais na fecundidade e fertilidade. A fim de avaliar os referidos parâmetros reprodutivos, 7 a 11 casais de 
adultos foram agrupados em gaiolas $(15,5 \mathrm{~cm}$ de altura x $18,5 \mathrm{~cm}$ de diâmetro) e, aproximadamente uma semana após a observação das primeiras posturas, quatro amostras de ovos, correspondendo cada uma aos ovos depositados em um período de 24 horas, foram coletadas em quatro dias consecutivos e incubadas para determinação do número médio de ovos/fêmea/dia e da porcentagem média de eclosão das larvas.

A redução na eclosão de larvas e a redução na emergência de adultos foram corrigidas em função da testemunha pela fórmula de SchneiderOrelli (PÜNTENER, 1981), e o efeito total de cada agrotóxico para pupas foi calculado por meio da fórmula proposta por VOGT (1992): $\mathrm{E}=100 \%$ - (100\% - R.E.A\%) x R1 x R2, em que: $\mathrm{E}=$ efeito total (\%); R.E.A.\% = redução na emergência de adultos; $\mathrm{R} 1$ = razão entre a média diária de ovos ovipositados por fêmea tratada e não tratada e R2 = razão entre a viabilidade média de ovos ovipositados por fêmea tratada e não tratada. Os agrotóxicos foram classificados para ovos em função da redução na eclosão e, para pupas, em função do efeito total, de acordo com as classes de toxicidade propostas pela International Organization for Biological and Integrated Control of Noxious Animals and Plants (IOBC), em: 1) inócuo (<30\%); 2) levemente nocivo $(30-79 \%)$; 3) moderadamente nocivo $(80-99 \%)$ e 4$)$ nocivo $(>99 \%)$.

Os dados referentes à viabilidade de ovos e pupas, assim como as médias de fecundidade e fertilidade, foram submetidos à análise de variância (ANOVA). A viabilidade média de ovos e pupas de cada tratamento foi comparada com a testemunha pelo teste de Dunnett, enquanto a comparação das médias de fecundidade e fertilidade se deu pelo teste de Tukey. As análises estatísticas foram realizadas através do software estatístico Assistat Versão 7.7 (SILVA \& AZEVEDO, 2009) - para uma probabilidade de erro de $5 \%$.

\section{RESULTADOS E DISCUSSÃO}

A viabilidade média de ovos, quando estes foram pulverizados com os agrotóxicos, variou de 28,13 a 95,83\% (Figura 1). A viabilidade de ovos não foi afetada significativamente pela maioria dos agrotóxicos, com exceção de folpete,

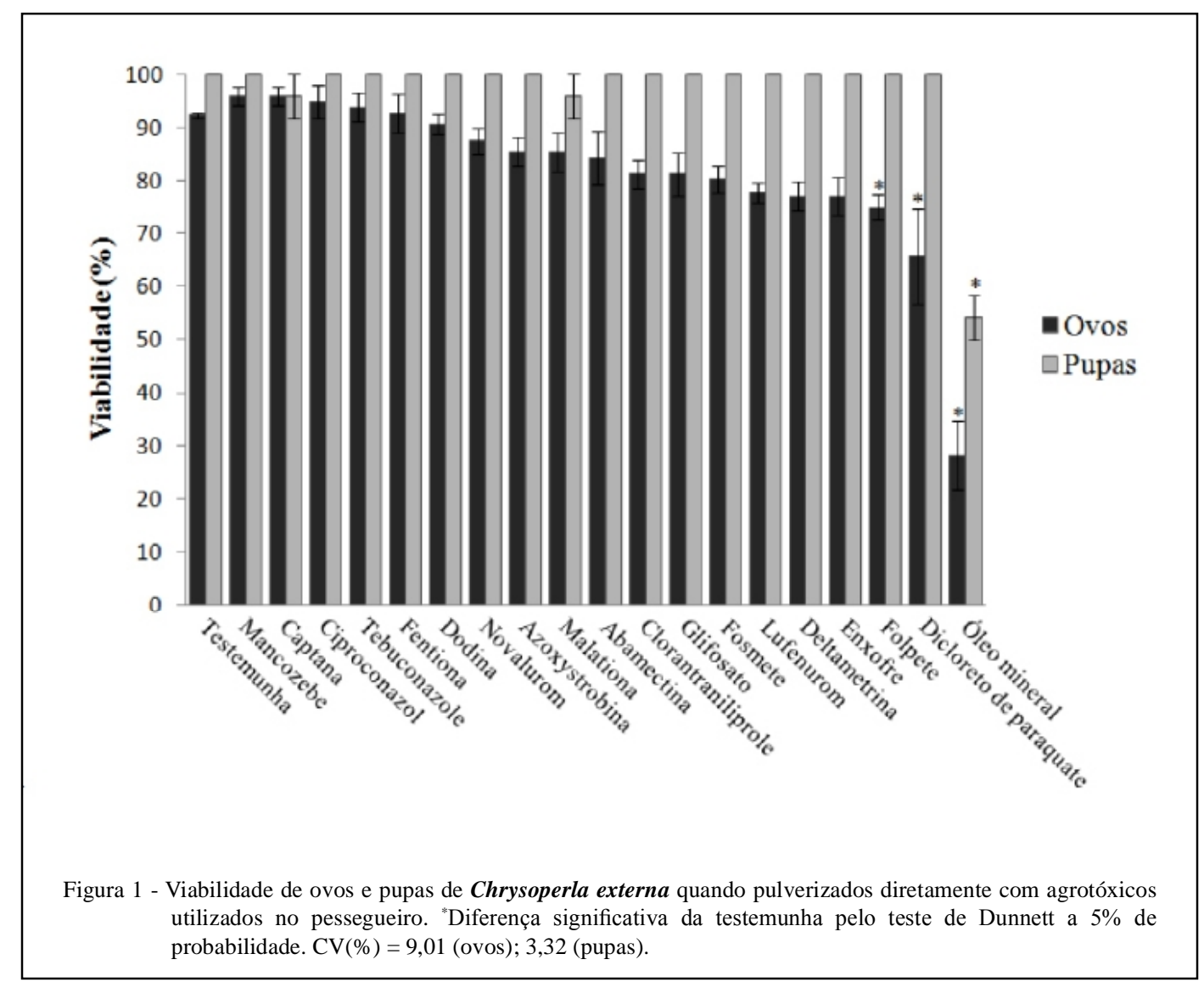

Ciência Rural, v.44, n.11, nov, 2014. 
dicloreto de paraquate e óleo mineral, em que as taxas de viabilidade observadas foram de 75,00; 65,63 e 28,13\%, respectivamente, diferindo significativamente da testemunha. Com base na redução na eclosão de larvas, óleo mineral foi considerado levemente nocivo (classe 2) a ovos de C. externa, com uma redução na eclosão de $69,55 \%$ (Tabela 1). Todos os demais agrotóxicos avaliados foram classificados como inócuos (classe 1) a ovos do predador, uma vez que reduziram a eclosão de larvas em menos de $30 \%$.

Efeito significativo na viabilidade de pupas foi observado somente para o óleo mineral, em que $54,17 \%$ das pupas pulverizadas foram viáveis. Para o fungicida captana e o inseticida malationa, a viabilidade de pupas foi de 95,83\%, sendo que, para os demais agrotóxicos, a viabilidade não foi reduzida (Figura 1). Com exceção de óleo mineral, captana e malationa, os agrotóxicos testados não causaram nenhuma redução na emergência de adultos. A fecundidade e fertilidade dos adultos de C. externa emergidos de pupas pulverizadas com os agrotóxicos não diferiram significativamente das obtidas na testemunha, demonstrando ausência de efeito subletal nos referidos parâmetros reprodutivos. Porém, diferenças significativas nestes parâmetros foram detectadas entre os diferentes tratamentos, em que a fecundidade proporcionada por dicloreto de paraquate foi menor que a proporcionada por novalurom, folpete e glifosato, enquanto a fertilidade

Tabela 1 - Redução na eclosão de larvas, redução na emergência de adultos, fecundidade e fertilidade de adultos emergidos, efeito total e consequente classificação de toxicidade para ovos e pupas de Chrysoperla externa.

\begin{tabular}{|c|c|c|c|c|c|c|c|c|}
\hline \multirow{2}{*}{ Tratamento } & \multirow{2}{*}{ \%i.a. ${ }^{1}$} & \multicolumn{2}{|c|}{------Ovos------- } & \multicolumn{5}{|c|}{ 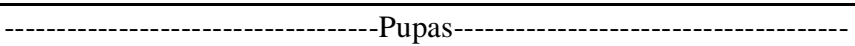 } \\
\hline & & R.E.L. ${ }^{2}$ & $\mathrm{C}^{3}$ & R.E.A. ${ }^{4}$ & Fecundidade & Fertilidade & $\mathrm{E}^{5}$ & $\mathrm{C}^{3}$ \\
\hline \multicolumn{9}{|c|}{ 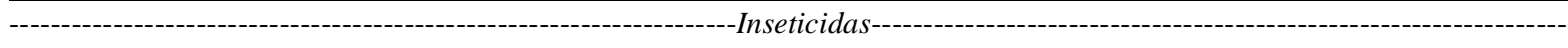 } \\
\hline Abamectina & 0,001 & 8,65 & 1 & 0,00 & $23,79 \pm 2,25 \mathrm{ab}$ & $79,44 \pm 2,81 \mathrm{abc}$ & 4,32 & 1 \\
\hline Chlorantraniliprole & 0,005 & 12,03 & 1 & 0,00 & $22,38 \pm 1,80 a b$ & $91,17 \pm 1,17 \mathrm{ab}$ & 0,00 & 1 \\
\hline Deltametrina & 0,001 & 16,54 & 1 & 0,00 & $26,25 \pm 0,69 a b$ & $74,75 \pm 3,00 \mathrm{bc}$ & 0,70 & 1 \\
\hline Fentiona & 0,050 & 0,00 & 1 & 0,00 & $24,00 \pm 2,65 \mathrm{ab}$ & $84,94 \pm 2,83 \mathrm{abc}$ & 0,00 & 1 \\
\hline Fosmete & 0,100 & 13,16 & 1 & 0,00 & $24,05 \pm 1,94 \mathrm{ab}$ & $80,46 \pm 4,44 a b c$ & 1,93 & 1 \\
\hline Lufenurom & 0,005 & 15,83 & 1 & 0,00 & $29,73 \pm 1,10 \mathrm{ab}$ & $82,76 \pm 2,52 \mathrm{abc}$ & 0,00 & 1 \\
\hline Malationa & 0,200 & 7,51 & 1 & 4,17 & $29,65 \pm 0,76 \mathrm{ab}$ & $94,19 \pm 1,26 \mathrm{a}$ & 0,00 & 1 \\
\hline Novalurom & 0,004 & 5,25 & 1 & 0,00 & $30,60 \pm 1,31 \mathrm{a}$ & $84,25 \pm 2,71 a b c$ & 0,00 & 1 \\
\hline Óleo mineral & 1,512 & 69,55 & 2 & 45.83 & $27,19 \pm 2,22 \mathrm{ab}$ & $85,53 \pm 2,40 a b c$ & 36,22 & 2 \\
\hline Azoxystrobina & 0,010 & 7,51 & 1 & 0,00 & $26,00 \pm 2,34 \mathrm{ab}$ & $71,99 \pm 4,83 \mathrm{bc}$ & 5,25 & 1 \\
\hline Captana & 0,120 & 0,00 & 1 & 4,17 & $25,07 \pm 3,07 \mathrm{ab}$ & $76,66 \pm 3,36 a b c$ & 6,76 & 1 \\
\hline Ciproconazol & 0,002 & 0,00 & 1 & 0,00 & $20,06 \pm 2,48 \mathrm{ab}$ & $75,82 \pm 2,23 \mathrm{abc}$ & 23,00 & 1 \\
\hline Dodina & 0,080 & 1,88 & 1 & 0,00 & $24,40 \pm 2,43 \mathrm{ab}$ & $75,97 \pm 3,64 a b c$ & 6,16 & 1 \\
\hline Enxofre & 0,480 & 16,54 & 1 & 0,00 & $25,84 \pm 2,14 \mathrm{ab}$ & $71,37 \pm 2,90 \mathrm{c}$ & 6,64 & 1 \\
\hline Folpete & 0,125 & 18,80 & 1 & 0,00 & $30,15 \pm 2,16 \mathrm{a}$ & $80,93 \pm 2,71 \mathrm{abc}$ & 0,00 & 1 \\
\hline Mancozebe & 0,160 & 0,00 & 1 & 0,00 & $22,92 \pm 2,02 \mathrm{ab}$ & $81,12 \pm 3,53 a b c$ & 5,87 & 1 \\
\hline Tebuconazole & 0,020 & 0,00 & 1 & 0,00 & $26,15 \pm 3,12 \mathrm{ab}$ & $80,44 \pm 2,59 a b c$ & 0,00 & 1 \\
\hline Dicloreto de Paraquate & 0,300 & 28,95 & 1 & $\begin{array}{l}\text { Herbicida } \\
0,00\end{array}$ & $19,25 \pm 1,75 b$ & $84,55 \pm 3,31 \mathrm{abc}$ & 17,6 & 1 \\
\hline Glifosato & 1,080 & 12,03 & 1 & 0,00 & $30,16 \pm 1,90 a$ & $72,85 \pm 9,98 \mathrm{bc}$ & 0,00 & 1 \\
\hline Testemunha & - & - & - & - & $24,32 \pm 0,88 \mathrm{ab}$ & $81,22 \pm 2,46 \mathrm{abc}$ & - & - \\
\hline CV $(\%)$ & & & & & 16,15 & 9,15 & & \\
\hline
\end{tabular}

${ }^{1} \%$ i.a. $=$ Concentração de ingrediente ativo na calda; ${ }^{2}$ R.E.L. $=$ Redução na eclosão de larvas corrigida por Schneider-Orelli $(\%) ;{ }^{3} \mathrm{C}=$ Classes da IOBC: $1=$ inócuo $(<30 \%), 2=$ levemente nocivo (30-79\%), 3=moderadamente nocivo $(80-99 \%), 4=$ nocivo $(>99 \%) .{ }^{4}$ R.E.A. = Redução na emergência de adultos corrigida por Schneider-Orelli $(\%) ;{ }^{5} \mathrm{E}=$ Efeito total $(\%)$; Médias seguidas pela mesma letra na coluna não diferem significativamente entre si pelo teste de Tukey a $5 \%$ de probabilidade. 
proporcionada por enxofre foi significativamente menor que a proporcionada por malationa $\mathrm{e}$ chlorantraniliprole (Tabela 1). Assim como em ovos, somente óleo mineral apresentou nocividade a pupas, sendo considerado levemente nocivo (classe 2). Os demais agrotóxicos foram inócuos a pupas, com um efeito total inferior a $30 \%$.

As propriedades físico-químicas dos agrotóxicos, juntamente com a barreira física protetora dos estágios de ovo e pupa são determinantes para a baixa toxicidade observada para a maioria dos agrotóxicos sobre estes estágios de desenvolvimento. Grande parte dos agrotóxicos, inclusive os inseticidas neurotóxicos, considerados de amplo espectro, como deltametrina, fentiona, fosmete e malationa não se mostraram tóxicos, em função de suas formulações não serem capazes de vencer a proteção do córion dos ovos e do casulo de seda das pupas, diferentemente do óleo mineral, cuja formulação comercial utilizada se caracteriza por promover melhor distribuição da calda sobre superfícies tratadas, diminuir a tensão superficial e facilitar a penetração do agrotóxico.

A falta de efeito ovicida da maioria dos inseticidas testados está de acordo com resultados obtidos por CARVALHO et al. (2002), os quais avaliaram a seletividade de cinco inseticidas de diferentes grupos químicos em ovos de $\boldsymbol{C}$. externa, e constataram que nenhum dos inseticidas reduziu significativamente a viabilidade de ovos do predador. Resultados obtidos com o organofosforado fosmete para ovos assemelham-se aos descritos por FERREIRA et al. (2005), que obtiveram viabilidade de $90,34 \%$ e classificaram o inseticida como inócuo a ovos de $\boldsymbol{C}$. externa. Da mesma forma, GIOLO et al. (2009) verificaram $100,00 \%$ de viabilidade em ovos de Chrysoperla carnea (Stephens) (Neuroptera: Chrysopidae) pulverizados com fosmete na mesma dosagem utilizada no presente estudo. Diferentemente, BASTOS et al. (2007) relataram que o inseticida organofosforado clorpirifós reduziu em mais de $50,00 \%$ a eclosão de larvas de $\boldsymbol{C}$. externa, porém os ovos foram imersos na calda por 5 segundos, ao invés de receberem pulverização direta, o que possivelmente possibilitou uma maior penetração do inseticida no córion do ovo.

O córion, como é denominada a camada externa dos ovos de insetos, apresenta normalmente textura rígida e se constitui na principal barreira de proteção do embrião contra agrotóxicos. No entanto, o córion possui aberturas ou áreas especializadas chamadas aerópilas, hidrópilas e micrópilas, as quais possibilitam as trocas gasosas, hídricas e penetração do espermatozoide, respectivamente (GALLO et al., 2002).
Para o piretroide deltametrina, GODOY et al. (2004a) obtiveram uma viabilidade de ovos de C. externa de $76,60 \%$, valor semelhante ao obtido no presente estudo $(77,08 \%)$ (Figura 1). Trabalhando com a espécie $\boldsymbol{C}$. carnea, GIOLO et al. (2009) também classificaram deltametrina como inócuo a ovos, com uma viabilidade de $94,30 \%$. A inocuidade do acaricida abamectina para ovos foi também relatada por MOURA et al. (2009a) para duas populações de $\boldsymbol{C}$. externa coletadas em pomares de macieira do Estado do Rio Grande do Sul, assim como BUENO \& FREITAS (2004), que não verificaram efeito nocivo de abamectina sobre ovos do predador em três diferentes concentrações. Resultados obtidos por CARVALHO et al. (2011) reforçam a ausência de efeito ovicida de acaricidas sobre crisopídeos. Para o inseticida regulador de crescimento lufenurom, GODOY et al. (2004a) obtiveram resultados que vão ao encontro do obtido no presente estudo e não verificaram efeito nocivo na viabilidade de ovos de C. externa.

A alta redução na eclosão de larvas, proporcionada por óleo mineral (Tabela 1), devese, muito provavelmente, ao efeito asfixiante deste inseticida, o qual, em função da sua formulação oleosa, bloqueou as aberturas do córion dos ovos, impedindo a respiração e consequente desenvolvimento do embrião. De acordo com HELMY et al. (2012), inseticidas a base de óleo mineral quando pulverizados sobre ovos de insetos formam uma fina camada sobre a sua superfície, o que impede as trocas gasosas. Além disso, causam o endurecimento do córion, dificultando a eclosão de larvas ou ninfas. $\mathrm{O}$ efeito nocivo de formulações oleosas sobre ovos de C. externa foi também relatado por BASTOS et al. (2007), que constataram que o óleo bruto de algodão afetou drasticamente a viabilidade de ovos.

$\mathrm{O}$ fato de todos fungicidas e herbicidas avaliados terem sido inócuos a ovos do predador (Tabela 1) pode ser atribuído, além da proteção física imposta pelo córion, a características dos agrotóxicos, que não possuem capacidade de atuar em nenhum sítio de ação que interfira na fisiologia deste inseto. Resultados obtidos por SILVA et al. (2012) com fungicidas vão de encontro ao afirmado, uma vez que os autores classificaram enxofre e oxicloreto de cobre como inócuos a ovos de $\boldsymbol{C}$. externa. A tolerância de ovos do predador a herbicidas também foi retalada por BASTOS et al. (2007), que obtiveram viabilidade de ovos superiores a $80 \%$ para ovos tratados com glifosato e paraquate + diuron.

Cabe ressaltar que, no presente estudo, a avaliação da toxicidade dos agrotóxicos sobre ovos 
se restringiu à verificação da redução na eclosão das larvas, porém possíveis efeitos subletais, como alterações na duração do período embrionário e efeitos nocivos em larvas e adultos oriundos de ovos tratados, podem influenciar no impacto de determinado agrotóxico sobre o estágio de ovo de $\boldsymbol{C}$. externa em pomares de pessegueiro.

De acordo com COSME et al. (2009), micrografias eletrônicas de varredura do casulo de seda de pupas de $\boldsymbol{C}$. externa revelaram que este apresenta diversos orifícios com aproximadamente $6 \mu \mathrm{m}$ de diâmetro, por onde ocorre a respiração do inseto. O bloqueio de orifícios respiratórios e consequente morte por asfixia é o principal modo de ação do óleo mineral, porém, em alguns casos, este inseticida causa toxicidade por meio da interação com ácidos graxos e interferência no metabolismo do inseto (HELMY et al., 2012). Substâncias de caráter hidrofóbico, como os óleos, possuem mais facilidade de transpor o tegumento de insetos (STEPHENSON \& SOLOMON, 2007), e o efeito adverso de óleo mineral sobre pupas (Figura 1; Tabela 1) pode estar também relacionado à maior capacidade de penetração pelos orifícios do casulo.

A ausência de efeito nocivo dos demais agrotóxicos a pupas de $\boldsymbol{C}$. externa vai ao encontro de vários trabalhos encontrados na literatura, que reportam a tolerância do estágio de pupa de crisopídeos a agrotóxicos. GODOY et al. (2004b), ao avaliarem o efeito de inseticidas utilizados no citros sobre pupas de $\boldsymbol{C}$. externa, obtiveram mortalidades que variaram de 0,00 a $16,7 \%$, e, assim como no presente estudo, classificaram os agrotóxicos abamectina e lufenurom como inócuos. Exceção se deu para deltametrina, que foi considerada levemente nociva a pupas pelos referidos autores, devido à menor fecundidade demonstrada pelas fêmeas emergidas. Do mesmo modo, SILVA et al. (2006) estudaram o efeito de inseticidas e fungicidas sobre pupas do predador, e constataram que mais de $80 \%$ dos produtos avaliados foram inócuos, entre eles o fungicida enxofre, que também se mostrou inócuo no presente estudo (Tabela 1). MOURA et al. (2009b) também observaram tolerância de pupas de C. externa a enxofre, reforçando a compatibilidade deste fungicida quando populações do predador se encontram no estágio de pupa em pomares.

A falta de efeito significativo dos agrotóxicos na fecundidade e fertilidade de adultos emergidos de pupas tratadas (Tabela 1) é importante para a viabilização do controle biológico exercido por $\boldsymbol{C}$. externa em pomares de pessegueiro, onde o controle químico é realizado, pois populações de inimigos naturais podem sucumbir, não só em função da mortalidade, mas por efeitos subletais que afetem a fisiologia ou o comportamento do inseto (DESNEUX et al., 2007). Resultados obtidos por MOURA et al. (2009b) também destacaram a ausência de efeito nos parâmetros reprodutivos de $\boldsymbol{C}$. externa, visto que a maioria dos agrotóxicos avaliados pelos autores não afetou a capacidade de oviposição de $\boldsymbol{C}$. externa oriundas de pupas tratadas. Uma vez que o casulo de seda atua como uma barreira física, a exposição do inseto aos agrotóxicos no interior da pupa se torna pouco provável, porém esta pode ocorrer na ocasião da emergência, quando o inseto adulto já formado rompe o casulo e assim entra em contato com resíduos depositados na parte externa do casulo. No entanto, esta possível exposição não foi suficiente para interferir nos processos reprodutivos de adultos.

Com base na importância do predador $\boldsymbol{C}$. externa para o controle biológico, a tolerância de ovos e pupas desta espécie a maioria dos agrotóxicos avaliados se constitui em fato relevante para manutençãodeumapopulaçãodopredadorempomares de pessegueiro, contribuindo consideravelmente para o MIP na cultura. Diante dessas informações, o uso de agrotóxicos que não afetam a eclosão de larvas e que se mostram inofensivos a pupas pode ser recomendado, principalmente em épocas em que os estágios de ovo e pupa do predador predominam em pomares de pessegueiro. Entretanto, para obtenção de informações mais precisas sobre o impacto destes agrotóxicos, quando pulverizados sobre ovos do predador, recomenda-se a avaliação dos efeitos subletais na progênie oriunda dos ovos tratados.

\section{CONCLUSÃO}

Para os agrotóxicos (\% de ingrediente ativo na calda), conclui-se que: os inseticidas abamectina $(0,001)$, clorantraniliprole $(0,005)$, deltametrina $(0,001)$, fentiona $(0,050)$, fosmete $(0,100)$, lufenurom $(0,005)$, malationa $(0,200)$ e novalurom $(0,004)$; os fungicidas azoxystrobina $(0,010)$, captana $(0,120)$, ciproconazol $(0,002)$, dodina $(0,080)$, enxofre $(0,480)$, folpete $(0,125)$, mancozebe $(0,160)$ e tebuconazole $(0,020)$ e os herbicidas dicloreto de paraquate $(0,300)$ e glifosato $(1,080)$ são inócuos (classe 1$)$, enquanto que óleo mineral $(1,512)$ é levemente nocivo (classe 2 ) a ovos e pupas de $\boldsymbol{C}$. externa.

\section{AGRADECIMENTOS}

À Coordenação de Aperfeiçoamento de Pessoal de Nível Superior (CAPES) pela bolsa de doutorado do primeiro autor e ao Conselho Nacional de Desenvolvimento Científico e Tecnológico $(\mathrm{CNPq})$ pelo financiamento da pesquisa. 


\section{REFERÊNCIAS}

AGROFIT (SISTEMA DE AGROTÓXICOS FITOSSANITÁRIOS). Disponível em: <http://agrofit.agricultura. gov.br/agrofit_cons/principal_agrofit_cons $>$. Acesso em: mar. 2010.

ATANASSOV, A. et al. Peach pest management programs impact beneficial fauna abundance and Grapholita molesta (Lepidoptera: Tortricidae) egg parasitism and predation. Environmental Entomology, v.32, n.4, p.780-788, 2003. Disponível em: <http://www.bioone.org/doi/abs/10.1603/0046225X-32.4.780?journalCode=enve >. Acesso em: 22 mar. 2014 doi: 10.1603/0046-225X-32.4.780.

BASTOS, C.S. et al. Seletividade de pesticidas à Chrysoperla externa (Hagen) (Neuroptera: Chrysopidae). Campina Grande: Embrapa Algodão, 2007. 4p. (Embrapa Algodão: Comunicado Técnico 346).

BUENO, A.F.; FREITAS, S. Effect of the insecticides abamectin and lufenuron on eggs and larvae of Chrysoperla externa under laboratory conditions. BioControl, v.49, n.3, p.277-283, 2004. Disponível em: <http://link.springer.com/article/10.1023/ B\%3ABICO.0000025375.07428.0b>. Acesso em: 13 abr. 2013. doi: 10.1023/B:BICO.0000025375.07428.0b.

CARVALHO, C.F.; SOUZA, B. Métodos de criação e produção de crisopídeos. In: BUENO, V.H.P. (Ed.). Controle biológico de pragas: produção massal e controle de qualidade. Lavras, UFLA. 2000. p.91-109.

CARVALHO, G.A. et al. Seletividade de inseticidas a Chrysoperla externa (Hagen) (Neuroptera: Chrysopidae). Neotropical Entomology, v.31, n.4, p.615-621, 2002. Disponível em: <http:// www.scielo.br/scielo.php?script=sci_arttext\&pid=S1519-566X20 $02000400015 \& \operatorname{lng}=\mathrm{en} \& \mathrm{nrm}=\mathrm{iso} \& \mathrm{t} \operatorname{lng}=\mathrm{pt}>$. Acesso em: 25 nov. 2012. doi: 10.1590/S1519-566X2002000400015.

CARVALHO, G.A. et al. Toxicidade de acaricidas a ovos adultos de Ceraeochrysa cubana (Hagen, 1861) (Neuroptera: Chrysopidae). Ciência e Agrotecnologia, v.35, n.1, p.165 171, 2011. Disponível em: <http://www.scielo.br/scielo. php script $=$ sci_arttext $\&$ pid $=$ S 1413-70542011000100021 \&lng=en\&nrm=iso\&tlng=pt $>$. Acesso em: 14 abr. 2013. doi: 10.1590/S1413-70542011000100021

COSME, L.V. et al. Toxicidade de óleo de nim para pupas e adultos de Chrysoperla externa (Hagen) (Neuroptera: Chrysopidae). Arquivos do Instituto Biológico, v.76, n.2, p.233-238, 2009. Disponível em: <http://www.biologico.sp.gov.br/docs/arq/v76_2/ cosme.pdf $>$. Acesso em: 01 maio, 2013.

DESNEUX, N. et al. The sublethal effects of pesticides on beneficial arthropods. Annual Review of Entomology, v.52, p.81-106, 2007. Disponível em: <http://www.annualreviews. org/doi/full/10.1146/annurev.ento.52.110405.091440> Acesso em: 01 maio, 2013. doi: 10.1146/annurev. ento.52.110405.091440

FACHINELLO, J.C. et al. Produção integrada de pêssego: Três anos de experiência na região de Pelotas-RS. Revista Brasileira de Fruticultura, v.25, n.2, p.256-258, 2003. Disponível em: <http://www.scielo.br/scielo.php?script=sci_arttext\&pid=S01002 $9452003000200018 \& \operatorname{lng}=\mathrm{pt} \& \mathrm{nrm}=\mathrm{iso} \& \operatorname{tng}=\mathrm{pt}>$. Acesso em: 12 abr. 2013. doi: 10.1590/S0100-29452003000200018
FERREIRA, A.J. et al. Seletividade de inseticidas usados na cultura da macieira a ovos de Chrysoperla externa (Hagen, 1861) (Neuroptera: Chrysopidae). Ciência Rural, v.35, n.4, p.756-762, 2005. Disponível em: <http://www.scielo.br/scielo. php?script=sci_arttext\&pid=S0103-84782005000400001\&lng=e $\mathrm{n} \& \mathrm{nrm}=\mathrm{iso} \& \operatorname{lng}=\mathrm{pt}>$. Acesso em: 13 abr. 2013. doi: 10.1590/ S0103-84782005000400001.

FREITAS, S. O uso de crisopídeos no controle biológico de pragas In: PARRA, J.R.P. et al. Controle biológico no Brasil: parasitóides e predadores. São Paulo: Manole, 2002. Cap.13, p.209-219.

GALLO, D. et al. Entomologia agrícola. Piracicaba: FEALQ, 2002. 920p.

GIOLO, F.P. et al. Effects of pesticides commonly used in peach orchards in Brazil on predatory lacewing Chrysoperla carnea under laboratory conditions. BioControl, v.54, n.5, p.625-635 2009. Disponível em: <http://link.springer.com/article/10.1007/ s10526-008-9197-2/fulltext.html>. Acesso em: 10 abr. 2013. doi: 10.1007/s10526-008-9197-2.

GODOY, M.S. et al. Seletividade de inseticidas utilizados na cultura dos citros para ovos e larvas de Chrysoperla externa (Hagen) (Neuroptera: Chrysopidae). Neotropical Entomology, v.33, n.5, p.639-646, 2004a. Disponível em: <http://www.scielo. br/scielo.php?script=sci_arttext\&pid=S1519-566X20040005000 $15 \& \operatorname{lng}=$ en $\& n r m=$ iso $\&$ tlng=pt $>$. Acesso em: 12 abr. 2013. doi 10.1590/S1519-566X2004000500015.

GODOY, M.S. et al. Seletividade de seis inseticidas utilizados em citros a pupas e adultos de Chrysoperla externa (Hagen) (Neuroptera: Chrysopidae). Neotropical Entomology, v.33, n.3, p.359-364, 2004b. Disponível em: <http://www.scielo.br/scielo. php?script=sci_arttext $\&$ pid $=$ S 1519-566X2004000300014\&lng=e n\&nrm=iso\&tlng=pt>. Acesso em: 12 abr. 2013. doi: 10.1590/ S1519-566X2004000300014.

HELMY, E.I. et al. The usage of mineral oils to control insects Egyptian Academic Journal of Biological Science, v.5, n.3, p.167-174, 2012. Disponível em: <http://entomology.eajbs.eg.net /pdf/vol5-num3/20.pdf>. Acesso em: 23 mar. 2014.

MEDINA, P. et al. Side effects of six insecticides on different developmental stages of Chrysoperla carnea (Neuroptera: Chrysopidae). IOBC/WPRS Bulletin, v.26, n.5, p.33-40, 2003. Disponível em: <http://www.iobc-wprs.org/pub/bulletins/iobcwprs_bulletin_2003_26_05.pdf>. Acesso em: 10 abr. 2013.

MOURA, A.P. et al. Toxicidade de pesticidas recomendados na produção integrada de maçã (PIM) a populações de Chrysoperla externa (Hagen) (Neuroptera: Chrysopidae). Neotropical Entomology, v.38, n.3, p.395-404, 2009a. Disponível em: <http:// www.scielo.br/scielo.php?script=sci_arttext\&pid=S1519-566X20 09000300016\&lng=en\&nrm=iso\&tlng=pt>. Acesso em: 12 abr. 2013. doi: 10.1590/S1519-566X2009000300016.

MOURA, A.P. et al. Efeitos da aplicação de agrotóxicos utilizados na produção integrada de maçã sobre pupas de Chrysoperla externa. Ciência Rural, v.39, n.8, p.2285-2292, 2009b. Disponível em: <http://www.scielo.br/scielo.php?script=sci_arttext\&pid=S0103$84782009000800003 \& \operatorname{lng}=\mathrm{en} \& \mathrm{nrm}=\mathrm{iso} \& \operatorname{tn} \mathrm{ln}=\mathrm{pt}>$. Acesso em: 20 abr. 2013. doi: 10.1590/S0103-84782009005000182.

NÖRNBERG, S.D. et al. Flutuação populacional e distribuição de Sitophilus zeamais em pomares de pessegueiro e macieira. 
Pesquisa Agropecuária Brasileira, v.48, n.4, p.358-364, 2013. Disponível em: <http://www.scielo.br/scielo.php?script=sci_ arttext\&pid=S0100-204X2013000400002\&lng=en \&nrm=iso $\&$ tlng=pt>. Acesso em: 2 maio, 2013. doi: 10.1590/S0100204X2013000400002.

PÜNTENER, W. Manual for field trials in plant protection. 2.ed. Basle: Ciba-Geigy, 1981. 205p.

SALLES, L.A.B. Principais pragas e seu controle. In: MEDEIROS, C.A.B.; RASEIRA, M.C. A cultura do pessegueiro. Brasília: Embrapa - CPACT, 1998. Cap.8, p.206-242.

SCHUBER, J.M. et al. Influência de sistemas de produção sobre a ocorrência de inimigos naturais de afídeos em pomares de pessegueiros em Araucária-PR. Revista Brasileira de Fruticultura, v.30, n.2, p.336-342, 2008. Disponível em: <http://www.scielo.br/scielo.php?script=sci_arttext\&pid=S0100$29452008000200012 \& \operatorname{lng}=p t \& n r m=i s o \& t \operatorname{lng}=p t>$. Acesso em: 10 abr. 2013. doi: 10.1590/S0100-29452008000200012.

SILVA, F.A.S.E.; AZEVEDO, C.A.V. Principal components analysis in the software Assistat - Statistical Attendance. In: WORLD CONGRESS ON COMPUTERS IN AGRICULTURE, 7., 2009, Reno-NV-USA. Annals... Reno: American Society of Agricultural and Biological Engineers, 2009. p.22-24.

SILVA, R.A. et al. Ação de produtos fitossanitários utilizados em cafeeiros sobre pupas e adultos de Chrysoperla externa (Hagen, 1861) (Neuroptera: Chrysopidae). Ciência Rural, v.36, n.1, p.8-14, 2006. Disponível em: <http://www.scielo.br/scielo. php?script=sci_arttext $\&$ pid $=$ S0103-84782006000100002\&lng=e $\mathrm{n} \& \mathrm{nrm}=\mathrm{iso} \& \operatorname{lng}=\mathrm{pt}>$. Acesso em: 20 abr. 2013. doi: 10.1590/ S0103-84782006000100002.

SILVA, R.A. et al. Effects of pesticides on eggs of Chrysoperla externa (Neuroptera: Chrysopidae) and consequences on subsequent development. Revista Colombiana de Entomología, v.38, n,1,p.58-63, 2012. Disponível em: <http://www.scielo.org.co/ scielo.php?script=sci_arttext\&pid=S0120-04882012000100009\& lng=pt\&nrm=is\&tlng=en>. Acesso em: 12 abr. 2013

SOARES, J.J. et al. Fatores que afetam a predação de Chrysoperla externa (Neuroptera: Chrysopidae). Campina Grande: Embrapa, 2002. 30p. (Embrapa Algodão, Documentos 100).

STEPHENSON, G.R.; SOLOMON, K.R. Pesticide uptake and movement in target organisms. In: Pesticides and the Environment. Guelph: CNTC, 2007. Cap.5, p.69-80.

VOGT, H. Untersuchungen zu nebenwirkungen von insektiziden und akariziden auf Chrysoperla carnea (Stephens) (Neuroptera: Chrysopidae). Mededelingen Rijksfaacuteit Landbouwwetenschappen te Gent, v.57, n.2b, p.559-567, 1992.

VOGT, H. et al. Laboratory method to test effects of plant protection products on larvae of Chrysoperla carnea (Neuroptera: Chrysopidae). In: CANDOLFI, M.P. et al. Guidelines to evaluate side-effects of plant protection products to non-target arthropods. Darmstadt: IOBC/ WPRS, 2000. p.27-44. 